\title{
Transcriptomic and proteomic analysis of potential therapeutic target genes in the liver of metformin-treated Sprague-Dawley rats with type 2 diabetes mellitus
}

\author{
YITAO CHEN $^{1 *}$, YANGSHENG WU ${ }^{2 *}$, YUANXIAO YANG ${ }^{2}$, ZHIWEI XU ${ }^{2}$, JUNFENG TONG $^{2}$, \\ ZHEMING LI ${ }^{2}$, XIAOJIE ZHOU ${ }^{2}$ and CHANGYU LI ${ }^{2}$ \\ Colleges of ${ }^{1}$ Life Science and ${ }^{2}$ Pharmacy, Zhejiang Chinese Medical University, \\ Hangzhou, Zhejiang 310053, P.R. China
}

Received December 15, 2016; Accepted January 31, 2018

DOI: $10.3892 /$ ijmm.2018.3535

\begin{abstract}
The main actions of metformin are as follows: To reduce hyperglycemia via the suppression of gluconeogenesis, improve glucose uptake and insulin sensitivity, and stimulate activation of adenosine monophosphate-activated protein kinase during the treatment of diabetes mellitus. It is well known that metformin acts via complex mechanisms, including multitarget and multipathway mechanisms; however, the multitargeted antidiabetic genes of metformin remain obscure. The present study aimed to perform transcriptomic and proteomic analysis of potential therapeutic target genes in the liver of metformin-treated Sprague-Dawley rats with type 2 diabetes mellitus. The type 2 diabetes rat model was established using streptozotocin. Fasting blood glucose, hemoglobin A1c, serum insulin and biological parameters were subsequently measured. Differentially expressed genes (DEGs) and proteins were identified in the rat livers by expression profile analysis and isobaric tags for relative and absolute quantitation (iTRAQ). A 1.5-fold alteration in gene expression, as determined using chip-based expression profile analysis, and a 1.2-fold alteration in protein expression, as determined using iTRAQ, were considered physiologically significant benchmarks, which were used to identify DEGS in metformin-treated rats with type 2 diabetes mellitus. The DEGs were verified using quantitative polymerase chain reaction (qPCR) and western blot analysis. Numerous hepatic genes involved in various metabolic pathways were affected by metformin; in particular, genes associated with lipid metabolism were markedly affected. Expression profile analysis
\end{abstract}

Correspondence to: Professor Changyu Li, College of Pharmacy, Zhejiang Chinese Medical University, 548 Binwen Road, Binjiang, Hangzhou, Zhejiang 310053, P.R. China

E-mail: 1cyzcmu@sina.com

*Contributed equally

Key words: gene chip, isobaric tags for relative and absolute quantitation, metformin, type 2 diabetes mellitus, cholesterol $7 \alpha$-hydroxylyase, carboxylesterase $1 \mathrm{C}$ subunit and iTRAQ analysis suggested that carboxylesterase $1 \mathrm{C}$ subunit (Ces1C) and cholesterol $7 \alpha$-hydroxylyase (Cyp7a1) may serve as important DEGs, which were validated by qPCR and western blot analysis. Ces1C and Cyp7a1 are the main enzymes in cholesterol metabolism, yet the result of western blotting was not consistent with qPCR. The present study demonstrated that metformin may affect the expression of numerous hepatic genes involved in metabolic pathways, particularly the lipid and cholesterol metabolic pathways. Ces1C and Cyp7a1 may be considered novel therapeutic target genes in the liver, which are involved in the antidiabetic effects of metformin.

\section{Introduction}

Diabetes mellitus refers to a group of metabolic diseases that are characterized by hyperglycemia, which results from defects in the secretion and/or action of insulin. The vast majority of cases of diabetes fall into two broad categories: Type 1 diabetes mellitus, which is caused by an absolute deficiency of insulin secretion; and type 2 diabetes mellitus (T2DM), which is caused by resistance to insulin action alongside an inadequate compensatory insulin secretory response (1). According to recent World Health Organization estimates, 347 million individuals have T2DM. The number of patients with diabetes is expected to rise to 438 million by 2030 , and $>135$ million people are affected by diabetes worldwide $(2,3)$. The degree of hyperglycemia is sufficient to induce pathological and functional alterations in various target tissues, thus resulting in an increased risk of developing various disease-associated microvascular and macrovascular complications, including hypertension, retinopathy, nephropathy, neuropathy, myocardial infarction and stroke (4). Therefore, the maintenance of normal plasma glucose levels is a key factor to delay or prevent the development of diabetes-associated complications $(5,6)$. Numerous drugs, including sulfonylurea, metformin and insulin injections, are able to control high blood glucose levels and prevent these complications. Among these drugs, metformin is widely prescribed to control blood glucose levels $(7,8)$, and is often administered as a preliminary drug to treat T2DM combined with other agents, including glimepiride and pioglitazone $(9,10)$. 
The liver serves as the 'metabolic center' of the body, and is involved in the metabolism of various molecules, including carbohydrates, lipids, proteins and hormones. Therefore, the liver serves a crucial role in the maintenance of material metabolism, which concerns the digestion, absorption, movement and decomposition of substances in the body, and energy metabolism. It is generally accepted that metformin reduces fasting blood glucose (FBG) levels by reducing the rate of hepatic glucose production (11). In a previous study, metformin was able to increase glucose utilization in muscles and fat synthesis (12). Further studies indicated that metformin may activate adenosine monophosphate-activated protein kinase (AMPK) in peripheral tissues, which is a major cellular regulator of lipid and glucose metabolism $(13,14)$, without stimulating insulin production (9). Therefore, it is clear that metformin exhibits antidiabetes efficacy via multitarget and multipathway mechanisms; however, the target genes associated with the mechanisms underlying the effects of metformin on glucose remain unclear (15). Network pharmacology is a systems biology-based methodology and technology, which is based on the fundamental concept that effective therapeutic drugs act on several, rather than single, targets $(16,17)$. These targets can be determined using molecular networks that integrate multidisciplinary concepts, including biochemical networks, bioinformatics and systems biology. The combination of network theory and 'omics' data may help to forecast off-target effects at a higher efficiency, which could improve drug discovery through a novel network mode of 'multiple targets, multiple effects, complex diseases' (18). Therefore, network analyses based on network pharmacology theories have garnered attention as a powerful tool to systematically reveal the complex mechanism of action of metformin. Unlike traditional pharmacology, network pharmacology considers the relationship between genes and/or proteins to determine biologically important genes, which may reveal the intricate mechanism underlying the disease or drug action through multiple genes and targets, rather than single genes and targets.

The present study aimed to reveal the interactions between representative genes and proteins underlying T2DM, in order to identify genes and proteins central to their topology and probe the molecular interactions between metformin and these targets. Furthermore, multitargeted antidiabetic genes targeted by metformin were determined by gene network and protein network analyses.

\section{Materials and methods}

Experimental animals and drug treatment. Male Sprague-Dawley rats (Shanghai SLAC Laboratory Animal Co., Ltd., Shanghai, China; age, 8 weeks; weight, 200 g) were used in the present study. Rats were housed ( $n=3 /$ cage) under a 12-h light/dark cycle at an ambient temperature of $22-25^{\circ} \mathrm{C}$. In addition, rats were fed a standard chow diet (Zhejiang Academy of Medical Sciences, Hangzhou, China) and water ad libitum for 2 weeks. T2DM was induced by injecting freshly prepared streptozotocin (STZ, 30 mg/kg, i.p.; Cas: 8883-66-4, Shanghai Haoran Biotechnology Co., Ltd, Shanghai, China) in cold citrate buffer $(0.1 \mathrm{M}, \mathrm{pH} 4.2)$ into overnight-fasted Sprague-Dawley rats. Normal Sprague-Dawley rats were fed a standard chow diet. T2DM Sprague-Dawley rats were fed a high-fat diet consisting of $69.75 \%$ standard chow diet, $10 \%$ lard, $10 \%$ yolk powder, $0.25 \%$ cholesterol and $10 \%$ sucrose (Zhejiang Academy of Medical Sciences). All rats were maintained under standard laboratory conditions for 11 weeks. Fasting blood glucose (FBG) was determined using a glucose meter (Accu-Chek Performa; Roche Diagnostics $\mathrm{GmbH}$, Mannheim, Germany) every 7 days, and diabetic rats exhibiting blood glucose levels between 15 and $25 \mathrm{mmol} / \mathrm{l}$ were selected to assess the antidiabetic activity of metformin. T2DM rats were randomly assigned into the T2DM group $(\mathrm{n}=11)$, in which diabetic rats received $10 \mathrm{ml} / \mathrm{kg} 0.25 \%$ sodium carboxymethyl cellulose (CMC-Na); and the metformin group $(n=10)$, in which diabetic rats received $200 \mathrm{mg} / \mathrm{kg}$ metformin (Sino-American Shanghai Squibb Pharmaceutical Ltd., Shanghai, China) dissolved in $0.25 \%$ CMC-Na once daily for 11 consecutive weeks by gavage. The normal group $(n=9)$ consisted of Sprague-Dawley rats treated with $10 \mathrm{ml} / \mathrm{kg}$ CMC-Na once daily for 11 consecutive weeks by gavage. Prior to treatment, measurements (at 0 weeks) of FBG, hemoglobin A1c (HbA1C), total cholesterol (TC), triglycerides (TG), high-density lipoprotein cholesterol (HDL-C), low-density lipoprotein cholesterol (LDL-C) and serum insulin levels were taken. FBG levels were measured every week and HbA1C was measured every month; however, TC, TG, HDL-C, LDL-C and serum insulin levels were measured at the 11th week only, and the rats were sacrificed. In addition, the rats underwent an oral glucose tolerance test. Blood samples were collected by puncturing the retro-orbital plexus under $10 \%$ chloral hydrate anesthesia (300 mg/kg, i.p), and rats were euthanized by rapid excision of the heart, liver, kidney, spleen, and skeletal muscle and fat tissues under anesthesia. Liver samples were weighed, quickly frozen in liquid nitrogen and stored at $-80^{\circ} \mathrm{C}$. The liver index and insulin sensitivity index were subsequently calculated. The rat experiments were conducted at the Zhejiang Chinese Medical University Laboratory Animal Research Center (Hangzhou, China; rodent licence no. SCXK 2013-2016), and the present study was approved by the Laboratory Animal Management and Welfare Ethics Review Committee of Zhejiang Chinese Medical University (permit no. ZSLL-2013-48). All animal experiments were undertaken according to the guidelines of the Laboratory Animal Management and Welfare Ethics Review Committee.

Measurement of biochemical parameters. Blood samples were collected from the tail vein after a 16-h fast. FBG levels and body weight were estimated every 7 days after the treatments. Glycated HbA1c was estimated using an automated analyzer (Que-Test Analyzer; Quotient Diagnostics Ltd., London, UK) every month. Individual rats were placed in metabolic cages to obtain 24-h urine collections, and daily urinary albumin excretion levels were measured. Metformin was administered to the overnight-fasted rats at the last administration, and after 1-h treatments, all animals were anesthetized with $10 \%$ chloral hydrate $(300 \mathrm{mg} / \mathrm{kg}$, i.p). Blood samples were obtained by puncturing the retro-orbital plexus and were stored with or without disodium EDTA to evaluate the biochemical parameters, including serum TC (cat. no. 113009910704), HDL-C (cat. no. 135219910704), LDL-C (cat. no. 141219910930) and TG (cat. no. 157109910717; all from DiaSys Diagnostic Systems GmbH, Frankfurt, Germany), using commercially 
available kits in a semi-auto analyzer (Photometer 4040; Riele, Berlin, Germany). Serum insulin levels were estimated using the ELISA method (cat. no. 10-1250-01; Mercodia AB, Uppsala, Sweden). The liver index was calculated as liver weight $(\mathrm{mg})$ /body weight $(\mathrm{g})$. Furthermore, insulin sensitivity index was calculated as $1 / \mathrm{FBG}(\mathrm{mmol} / \mathrm{l}) \mathrm{x}$ serum insulin $(\mu \mathrm{g} / \mathrm{l})$.

Microarray experiment. Total RNA was extracted from liver tissues ( $n=6 /$ group) following treatment using the miRNeasy kit (217004; Qiagen, Inc., Valencia, CA, USA) according to the manufacturer's protocol. Isolated RNA was considered pure if the ratio of absorbance readings at 260 and $280 \mathrm{~nm}$ was 1.7:2.1. A total of $250 \mathrm{ng}$ quality-checked total cellular RNA was reverse transcribed using the Low-input RNA Linear Amplification kit (Agilent Technologies, Inc., Santa Clara, CA, USA) and was then transcribed into Cy3-labeled cRNA according to the manufacturer's protocol. The labeled cRNA was purified using the RNeasy kit (Qiagen, Inc.), and the dye content ( $>9.0 \mathrm{pmol}$ dye $/ \mathrm{mg}$ cRNA) and concentration of cRNA were measured using a NanoDrop ND-1000 spectrophotometer (NanoDrop Technologies; Thermo Fisher Scientific, Inc., Wilmington, DE, USA). A total of 1,650 ng Cy3-labeled cRNA was hybridized to Whole Rat Genome Oligo 4x44K microarrays (Agilent Technologies, Inc.) overnight at $65^{\circ} \mathrm{C}$, after which the slides were washed and treated with Stabilization and Drying Solution, and were scanned using Agilent Microarray Scanner (both from Agilent Technologies, Inc.). All steps were performed according to the manufacturer's protocols.

Gene expression data and network analysis. All microarray data were extracted using GenePix ${ }^{\circledR}$ pro 6.1 (Molecular Devices, LLC, Sunnyvale, CA, USA). The data were normalized using Agilent_Analyze_V1.0 (Agilent Technologies, Inc.), with default parameter settings for one-color oligonucleotide microarrays, after which the statistics were further analyzed. Genes with a $>1.5$-fold differential expression were further analyzed using statistical analyses. An unpaired t-test was used to compare the groups. The Benjamini-Hochberg multiple testing correction method was applied with a $\mathrm{P}<0.05$ cutoff. For gene network analysis, gene symbols, Agilent probe IDs, and the fold change of the differentially expressed genes (DEGs; metformin-treated samples vs. T2DM samples, and T2DM samples vs. control samples) were imported into GeneMANIA software (http://www.genemania.org). In GeneMANIA, the analysis was conducted with $\mathrm{P}<0.05$ as the cut-off point. Genes with known gene symbols and their corresponding expression values were uploaded into the software. Each gene symbol was mapped to its corresponding gene object in the Ingenuity Pathways Knowledge Base. A Kyoto Encyclopedia of Genes and Genomes (KEGG) pathway and the Gene Ontology (GO) enrichment analysis was performed using the Database for Annotation, Visualization and Integrated Discovery (DAVID; https://david.ncifcrf.gov/home. jsp) 6.7 tools to obtain the biological meaning of the networks.

Protein preparation. Liver samples acquired from the control, T2DM and metformin groups ( $\mathrm{n}=6 /$ group) were ground into powder in liquid nitrogen and proteins were extracted using lysis buffer, which consisted of $7 \mathrm{M}$ urea, $2 \mathrm{M}$ thiourea, $4 \%$ 3-[(3-cholamidopropyl)dimethylammonio]-1-propanesulfonate and $40 \mathrm{mM}$ Tris- $\mathrm{HCl}$ ( $\mathrm{pH} 8.5$ ) containing $1 \mathrm{mM}$ phenylmeth- ylsulfonyl fluoride and $2 \mathrm{mM}$ EDTA. After $5 \mathrm{~min}, 10 \mathrm{mM}$ dithiothreitol (DTT) was added to the samples. The suspension was sonicated at $200 \mathrm{~W}$ for $15 \mathrm{~min}$, and was then centrifuged at $4^{\circ} \mathrm{C}$ and $30,000 \mathrm{x} \mathrm{g}$ for $15 \mathrm{~min}$. The supernatant was mixed well with $5 \mathrm{X}$ chilled acetone containing $10 \%$ (v/v) trichloroacetic acid and was incubated at $-20^{\circ} \mathrm{C}$ overnight. Following centrifugation at $4^{\circ} \mathrm{C}$ and $30,000 \mathrm{x}$ g for $15 \mathrm{~min}$, the supernatant was discarded. The precipitate was washed three times with chilled acetone. The pellet was air-dried and dissolved in lysis buffer [7 M urea, $2 \mathrm{M}$ thiourea, 4\% NP-40 and $20 \mathrm{mM}$ Tris- $\mathrm{HCl}$ ( $\mathrm{pH}$ 8.0-8.5)]. The suspension was sonicated at $200 \mathrm{~W}$ for $15 \mathrm{~min}$, and was then centrifuged at $4^{\circ} \mathrm{C}$ and $30,000 \mathrm{x} \mathrm{g}$ for $15 \mathrm{~min}$. The supernatant was transferred to another tube. To reduce the disulfide bonds in proteins in the supernatant, $10 \mathrm{mM}$ DTT was added and the samples were incubated at $56^{\circ} \mathrm{C}$ for $1 \mathrm{~h}$. Subsequently, $55 \mathrm{mM}$ iodoacetamide was added to block the cysteines and the samples were incubated for $1 \mathrm{~h}$ in the dark at $4^{\circ} \mathrm{C}$. The supernatant was then mixed well with $5 \mathrm{X}$ chilled acetone for $2 \mathrm{~h}$ at $-20^{\circ} \mathrm{C}$ to precipitate proteins. Following centrifugation at $4^{\circ} \mathrm{C}$ and $30,000 \times \mathrm{g}$ for $15 \mathrm{~min}$, the pellet was air-dried for $5 \mathrm{~min}$, dissolved in $500 \mu \mathrm{l} 0.5 \mathrm{M}$ triethylammoniumbicarbonate (TEAB) (Applied Biosystems; Thermo Fisher Scientific, Inc., Waltham, MA, USA) and sonicated at $200 \mathrm{~W}$ for $15 \mathrm{~min}$. Finally, the samples were centrifuged at $4^{\circ} \mathrm{C}$ and $30,000 \mathrm{x}$ g for $15 \mathrm{~min}$. The supernatant was transferred to a new tube and quantified using a 2-D Quant kit (GE Healthcare Life Sciences, Little Chalfont, UK). The proteins in the supernatant were maintained at $-80^{\circ} \mathrm{C}$ for further analysis.

Isobaric tags for relative and absolute quantitation (iTRAQ) labeling and strong cation exchange (SCX) fractionation. iTRAQ marker technology is an effective method used to study cells or tissues in various physiological states, and to determine specific protein markers. Total proteins $(100 \mu \mathrm{g})$ from each sample were digested with Trypsin Gold (Promega Corporation, Madison, WI, USA) in a ratio of $30: 1$ at $37^{\circ} \mathrm{C}$ for $16 \mathrm{~h}$. After trypsin digestion, peptides were dried by vacuum centrifugation. Peptides were reconstituted in $0.5 \mathrm{M}$ TEAB and processed using 8-plex iTRAQ reagent (Applied Biosystems; Thermo Fisher Scientific, Inc.) according to the manufacturer's protocol. The samples were labeled with the iTRAQ tags as follows: Normal samples (114 tag), T2DM samples (116 tag) and metformin samples (118 tag). The labeled peptide mixtures were then pooled and dried by vacuum centrifugation. Subsequently, the labeled peptides were pooled and purified using a SCX chromatography column (Phenomenex, Inc., Torrance, CA, USA), and were separated by liquid chromatography (LC) using a LC-20AB HPLC Pump system (Shimadzu Corporation, Kyoto, Japan). The iTRAQ-labeled peptide mixtures were reconstituted with $4 \mathrm{ml}$ buffer A [25 mM $\mathrm{NaH}_{2} \mathrm{PO}_{4}$ in $25 \%$ acetonitrile (ACN), $\left.\mathrm{pH} 2.7\right]$ and loaded onto a 4.6x250 mm Ultremex SCX column containing 5- $\mu \mathrm{m}$ particles (Phenomenex, Inc.). The peptides were eluted at a flow rate of $1 \mathrm{ml} / \mathrm{min}$ with a gradient of buffer A for $10 \mathrm{~min}, 5-60 \%$ buffer $\mathrm{B}\left(25 \mathrm{mM} \mathrm{NaH}_{2} \mathrm{PO}_{4}, 1 \mathrm{M} \mathrm{KCl}\right.$ in $\left.25 \% \mathrm{ACN}, \mathrm{pH} 2.7\right)$ for $27 \mathrm{~min}$, and $60-100 \%$ buffer B for $1 \mathrm{~min}$. The system was then maintained at $100 \%$ buffer B for 1 min prior to equilibrating with buffer A for $10 \mathrm{~min}$ before the next injection. Elution was monitored by measuring the absorbance at $214 \mathrm{~nm}$, and fractions were collected every $1 \mathrm{~min}$. The eluted peptides were 
pooled into 20 fractions, desalted with a Strata X C18 column (Phenomenex, Inc.), and vacuum-dried.

LC-electrospray ionization-tandem mass spectrometry (LC-ESI-MS/MS) analysis based on Triple time-of-flight (TOF) 5600. Each fraction was resuspended in buffer A [5\% ACN, $0.1 \%$ formic acid (FA)] and centrifuged at 20,000 $\mathrm{x} g$ for $10 \mathrm{~min}$; the final concentration of the peptide was $\sim 0.5 \mu \mathrm{g} / \mu \mathrm{l}$. Subsequently, $10 \mu \mathrm{l}$ supernatant was loaded on a LC-20AD nano-HPLC (Shimadzu Corporation) using an autosampler onto a 2-cm C18 trap column. The peptides were then eluted onto a $10-\mathrm{cm}$ analytical C18 column (inner diameter, $75 \mu \mathrm{m}$ ) packed in-house. The samples were loaded at $8 \mu \mathrm{l} / \mathrm{min}$ for $4 \mathrm{~min}$; the $35-\mathrm{min}$ gradient was run at $300 \mathrm{nl} / \mathrm{min}$ starting at 2 to $35 \%$ buffer B (95\% ACN, $0.1 \%$ FA), followed by 5 -min linear gradient to $60 \%$, then 2-min linear gradient to $80 \%$, and maintenance at $80 \%$ buffer B for 4 min. Finally, buffer B was returned to $5 \%$ in $1 \mathrm{~min}$. Data acquisition was performed using a Triple TOF 5600 system fitted with a Nanospray III source (SCIEX, Framingham, MA, USA) with a pulled quartz tip as the emitter (New Objective, Inc., Woburn, MA, USA). Data were acquired using an ion spray voltage of $2.5 \mathrm{kV}$, curtain gas of $30 \mathrm{psi}$, nebulizer gas of $15 \mathrm{psi}$, and an interface temperature of $150^{\circ} \mathrm{C}$. Mass spectrometry (MS) was operated with a reversed phase $\geq 30,000$ FWHM for TOF MS scans. For information-dependent acquisition, survey scans were acquired in $250 \mathrm{msec}$, and as many as 30 product ion scans were collected if exceeding a threshold of 120 counts per second and with a $2^{+}$to $5^{+}$charge state. Total cycle time was fixed to $3.3 \mathrm{sec}$. The Q2 transmission window was $100 \mathrm{kDa}$ for $100 \%$. Particle signal was obtained at a pulser frequency value of $11 \mathrm{kHz}$ via monitoring of the $40-\mathrm{GHz}$ multichannel time-to-digital detector with a four-anode channel to record four times for combined transformation. A sweeping collision energy setting of $35 \pm 5 \mathrm{eV}$ coupled with iTRAQ adjust rolling collision energy was applied to all precursor ions for collision-induced dissociation. Dynamic exclusion was set for $1 / 2$ of peak width $(15 \mathrm{sec})$, and the precursor was refreshed off the exclusion list.

Protein data and network analysis. Raw data files acquired from the Orbitrap (Thermo Fisher Scientific, Inc.) were converted into Mascot Generic Format (MGF) files using Proteome Discoverer 1.2 (PD 1.2; Thermo Fisher Scientific, Inc.), and the MGF files were searched. Protein identification was performed using Mascot search engine (Matrix Science Ltd., London, UK). The parameters used included Gln- > pyro-Glu (N-term Q), oxidation (M) and deamidated (NQ) as the potential variable modifications; and carbamidomethyl (C), iTRAQ8plex (N-term) and iTRAQ8plex $(\mathrm{K})$ as the fixed modifications. The charge states of peptides were set to $2^{+}$and $3^{+}$. iTRAQ data from three biological replicates were analyzed using Mascot 2.3.02 software (Matrix Science Ltd.) and protein identification was performed using the most recently updated IPI_Rat V 3.87 SwissProt database (39,925 sequences; http://www.gpmaw.com/ $\mathrm{html} / \mathrm{swiss}$-prot.html). To reduce the probability of false peptide identification, only peptides with significance scores $(\geq 20)$ at the $99 \%$ confidence interval, as determined by a Mascot probability analysis, greater than 'identity' were counted as identified. Each confident protein identification involved at least one unique peptide. For protein quantization, it was required that a protein must contain at least two unique peptides. The quantitative protein ratios were weighed and normalized by the median ratio in Mascot. Only ratios with $\mathrm{P}<0.05$ and fold changes $>1.2$ were considered significant. Functional annotations of the proteins were conducted using Blast2GO program against the nonredundant protein database (https://www.blast2go.com/). The KEGG database (http://www.genome.jp/kegg/) and the COG database (http://www.ncbi.nlm.nih.gov/COG/) were used to classify and group these identified proteins.

Screening DEGs with microarray and iTRAQ. Genes with a $>1.5$-fold differential expression and proteins with a $>1.2$-fold differential expression were further analyzed. To identify the key genes involved in T2DM, microarray and iTRAQ analysis was used to analyze the same expressed trend (up or down) of the genes. The key genes upregulated or downregulated in both microarray and iTRAQ analyses were verified using quantitative polymerase chain reaction (qPCR) and western blot analysis.

Verification of DEGs with qPCR and western blot analysis. Total RNA was extracted from the tissues using TRIzol ${ }^{\circledR}$ (Invitrogen; Thermo Fisher Scientific, Inc.) according to the manufacturer's protocol. cDNA was then synthesized using a reverse transcription kit (Thermo Fisher Scientific, Inc.) according to the manufacturer's protocol. The cycling conditions for reverse transcription were as follows: $42^{\circ} \mathrm{C}$ for $60 \mathrm{~min}$ to start the reaction and $70^{\circ} \mathrm{C}$ for $5 \mathrm{~min}$ to terminate the reaction, after which the samples were immediately cooled on ice. cDNA was used as a template for qPCR, which was conducted using the following primers purchased from Sangon Biotech Co., Ltd. (Shanghai, China): Carboxylesterase 1C subunit (Ces1C), upstream 5'-AAGCAAGAGTTTGGCTGGAT-3', downstream 5'-TTAGGGCTGAACCTCCTCAA-3' (106 bp); cholesterol $7 \alpha$-hydroxylyase (Cyp7a1), upstream 5'-GCATCTCAA GCAAACACCAT-3', downstream 5'-TCCACTCACTTCTTC AGAGGC-3' (98 bp); and $\beta$-actin, upstream 5'-GCTCTCTTC CAGCCTTCCTT-3' and downstream 5'-GGTCTTTACGGA TGTCAACG-3' (105 bp). qPCR was performed using an Eppendorf RealPlex 4 Real-Time PCR Machine (Eppendorf, Hamburg, Germany); $\beta$-actin was used as an internal normalization control. The qPCR thermocycling conditions were as follows: pre-denaturation at $95^{\circ} \mathrm{C}$ for $30 \mathrm{sec}$, followed by 40 cycles of denaturation at $95^{\circ} \mathrm{C}$ for $5 \mathrm{sec}$ and annealing at $60^{\circ} \mathrm{C}$ for $30 \mathrm{sec}$. The dissolution curve conditions were $65^{\circ} \mathrm{C}$ for $0.05 \mathrm{sec}$ and $95^{\circ} \mathrm{C}$ for $0.5 \mathrm{sec}$. The results were presented as the fold change in gene expression relative to that of $\beta$-actin $\left(2^{-\Delta \Delta C q}\right)$ (19).

For western blotting, tissues were lysed in lysis buffer (Beyotime Institute of Biotechnology, Haimen, China) for $30 \mathrm{~min}$ on ice. The lysates were separated by centrifugation at $12,000 \mathrm{x} \mathrm{g}$ for $15 \mathrm{~min}$ at $4^{\circ} \mathrm{C}$. The total protein concentration in the supernatants was detected using Bicinchoninic Acid Protein assay kit (Nanjing KeyGen Biotech Co., Ltd., Nanjing, China). SDS-PAGE was performed using 10\% standard polyacrylamide gels, and $20 \mu \mathrm{g}$ protein was loaded onto gels. Proteins were subsequently transferred to polyvinylidene fluoride membranes, which were saturated with $5 \%$ milk in Tris-buffered saline and 1\% Tween-20 (TBST) at $4^{\circ} \mathrm{C}$ for $2 \mathrm{~h}$, and were then incubated with primary antibodies against Ces1C (1:2,000; rabbit polyclonal, ab193485; Abcam, Cambridge, MA, USA), Cyp7a1 (1:1,000; rabbit polyclonal, sc-25536; Santa Cruz 
Table I. Comparison of average food intake and body weight among the treatment groups.

\begin{tabular}{|c|c|c|c|c|c|c|c|}
\hline Group & 0 week & 1 week & 3 week & 5 week & 7 week & 9 week & 11 week \\
\hline \multicolumn{8}{|l|}{ Food intake } \\
\hline Con & $23.62 \pm 3.17$ & $18.28 \pm 6.06^{\mathrm{a}}$ & $25.10 \pm 4.51$ & $23.72 \pm 5.29^{a}$ & $24.88 \pm 3.11^{\mathrm{a}}$ & $19.97 \pm 3.05^{\mathrm{a}}$ & $20.37 \pm 3.43^{b}$ \\
\hline $\mathrm{T} 2 \mathrm{DM}$ & $28.20 \pm 6.32$ & $28.55 \pm 4.76$ & $29.82 \pm 5.23$ & $33.32 \pm 4.97$ & $34.40 \pm 6.90$ & $31.98 \pm 5.38$ & $30.32 \pm 3.78$ \\
\hline Metformin & $30.17 \pm 8.77$ & $27.65 \pm 5.96$ & $31.53 \pm 4.16$ & $30.53 \pm 5.13$ & $28.08 \pm 7.62$ & $38.50 \pm 11.16$ & $27.43 \pm 8.26$ \\
\hline \multicolumn{8}{|l|}{ Body weight } \\
\hline Con & $435.83 \pm 29.78$ & $440.17 \pm 37.68$ & $465.50 \pm 26.93$ & $480.34 \pm 38.01$ & $479.00 \pm 28.81$ & $524.67 \pm 29.56$ & $532.75 \pm 31.08^{a}$ \\
\hline $\mathrm{T} 2 \mathrm{DM}$ & $456.00 \pm 26.55$ & $438.17 \pm 28.90$ & $447.67 \pm 27.92$ & $457.17 \pm 42.54$ & $451.17 \pm 41.06$ & $469.17 \pm 43.59$ & $411.50 \pm 34.06$ \\
\hline Metformin & $465.33 \pm 62.18$ & $416.00 \pm 28.24$ & $414.00 \pm 47.39$ & $437.17 \pm 42.94$ & $447.83 \pm 47.09$ & $456.83 \pm 48.81$ & $430.83 \pm 43.60$ \\
\hline
\end{tabular}

Data are presented as the means \pm standard deviation (g/day). ${ }^{a} \mathrm{P}<0.01$ and ${ }^{\mathrm{b}} \mathrm{P}<0.05$ compared with the T2DM group. Con, control; T2DM, type 2 diabetes mellitus.
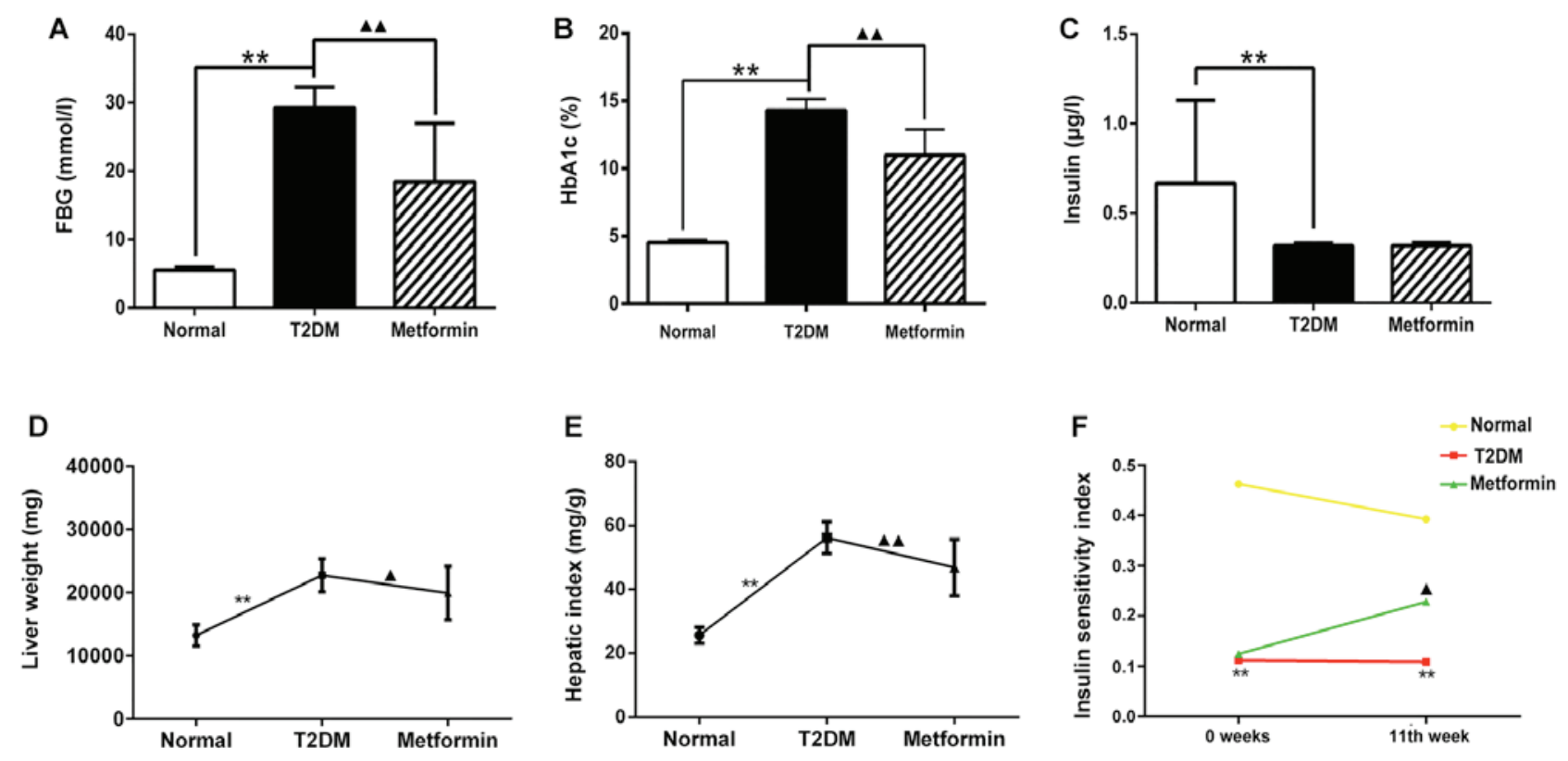

Figure 1. Effects of metformin on (A) FBG, (B) HbAlc, (C) serum insulin levels, (D) liver weight, (E) hepatic index and (F) insulin sensitivity index in rats with T2DM. Data are presented as the means \pm standard deviation. ${ }^{* *} \mathrm{P}<0.01$ the $\mathrm{T} 2 \mathrm{DM}$ group vs. the normal group; ${ }^{\wedge} \mathrm{P}<0.05$ and ${ }^{\wedge} \mathrm{P}<0.01$ the $\mathrm{T} 2 \mathrm{DM}$ group vs. the metformin group. FPG, fasting plasma glucose; HbA1C, hemoglobin A1c; T2DM, type 2 diabetes mellitus.

Biotechnology, Inc., Dallas, TX, USA), and $\beta$-actin $(1: 1,000$; mouse monoclonal, sc-47778; Santa Cruz Biotechnology, Inc.) overnight at $4^{\circ} \mathrm{C}$. Membranes were washed three times with TBST and were incubated with goat anti-rabbit immunoglobulin G-horseradish peroxidase (1:1,000; cat. no. A0208) or goat anti-mouse immunoglobulin G (1:1,000; cat. no. A0216; both from Beyotime Institute of Biotechnology) for $2 \mathrm{~h}$. The blots were then washed three times with TBST at room temperature and were developed on photographic film by an Omega Lum G Image Capture software (version 81-12100-00; Gel company, Inc., San Francisco, CA, USA) in a dark room using enhanced chemiluminescence solution (cat. no. P0018A; Beyotime Institute of Biotechnology).

Statistical analysis. The independent experiments were repeated 3 times and all results are presented as the means \pm standard deviation. Results were statistically analyzed using one-way analysis of variance. Statistical analysis was conducted using SPSS 17.0 (SPSS, Inc., Chicago, IL, USA) and the figures were produced using GraphPad Prism 5 (GraphPad Software, Inc., La Jolla, CA, USA). P<0.05 was considered to indicate a statistically significant difference.

\section{Results}

Effects of metformin on FBG, HbAlc, liver weight, liver index, serum insulin levels and insulin sensitivity index in rats with T2DM. The levels of FBG, HbA1C and insulin were measured from sera collected by puncturing the retro-orbital plexus at week 11. The results demonstrated that the T2DM group had high levels of FBG and $\mathrm{HbA1C}$, and low insulin levels compared with in the normal group (Fig. 1A-C; $\mathrm{P}<0.01$ ). Following treatment with metformin, FBG and HbA1C levels were markedly decreased compared with in the T2DM group $(\mathrm{P}<0.01)$; however, the insulin 
Table II. Comparison of average water intake and urine weight among the treatment groups.

\begin{tabular}{lccccccc}
\hline Group & 0 week & 1 week & 3 week & 5 week & 7 week & 9 week & 11 week \\
\hline Water intake & & & & & & & \\
Con & $51.13 \pm 9.64^{\mathrm{a}}$ & $71.83 \pm 17.42^{\mathrm{a}}$ & $49.25 \pm 11.19^{\mathrm{a}}$ & $52.52 \pm 15.41^{\mathrm{a}}$ & $53.48 \pm 12.55^{\mathrm{a}}$ & $49.02 \pm 19.00^{\mathrm{a}}$ & $49.55 \pm 20.36^{\mathrm{a}}$ \\
T2DM & $113.10 \pm 41.39$ & $116.98 \pm 13.24$ & $131.45 \pm 29.69$ & $149.70 \pm 33.89$ & $137.13 \pm 24.52$ & $130.25 \pm 28.07$ & $157.53 \pm 17.59$ \\
Metformin & $128.26 \pm 11.66$ & $109.70 \pm 27.49$ & $123.98 \pm 23.09$ & $127.67 \pm 15.96$ & $103.55 \pm 16.88^{\mathrm{b}}$ & $91.72 \pm 31.10^{\mathrm{b}}$ & $87.95 \pm 37.33^{\mathrm{a}}$ \\
Urine weight & & & & & & & \\
Con & $29.70 \pm 9.45^{\mathrm{a}}$ & $41.43 \pm 18.06^{\mathrm{a}}$ & $35.75 \pm 10.40^{\mathrm{a}}$ & $32.02 \pm 13.22^{\mathrm{a}}$ & $31.18 \pm 12.37^{\mathrm{a}}$ & $39.03 \pm 16.13^{\mathrm{a}}$ & $36.72 \pm 16.88^{\mathrm{a}}$ \\
T2DM & $85.38 \pm 27.93$ & $96.25 \pm 20.83$ & $99.13 \pm 28.57$ & $129.87 \pm 27.76$ & $115.42 \pm 16.46$ & $119.87 \pm 20.27$ & $134.50 \pm 17.75$ \\
Metformin & $94.35 \pm 26.77$ & $72.10 \pm 27.99^{\mathrm{b}}$ & $86.63 \pm 22.75$ & $101.98 \pm 19.67^{\mathrm{b}}$ & $68.10 \pm 29.52^{\mathrm{a}}$ & $65.18 \pm 29.54^{\mathrm{a}}$ & $65.18 \pm 29.94^{\mathrm{a}}$ \\
\hline
\end{tabular}

Data are presented as the means \pm standard deviation (g/day). ${ }^{\mathrm{a}} \mathrm{P}<0.01$ and ${ }^{\mathrm{b}} \mathrm{P}<0.05$ compared with the T2DM group. Con, control; T2DM, type 2 diabetes mellitus.
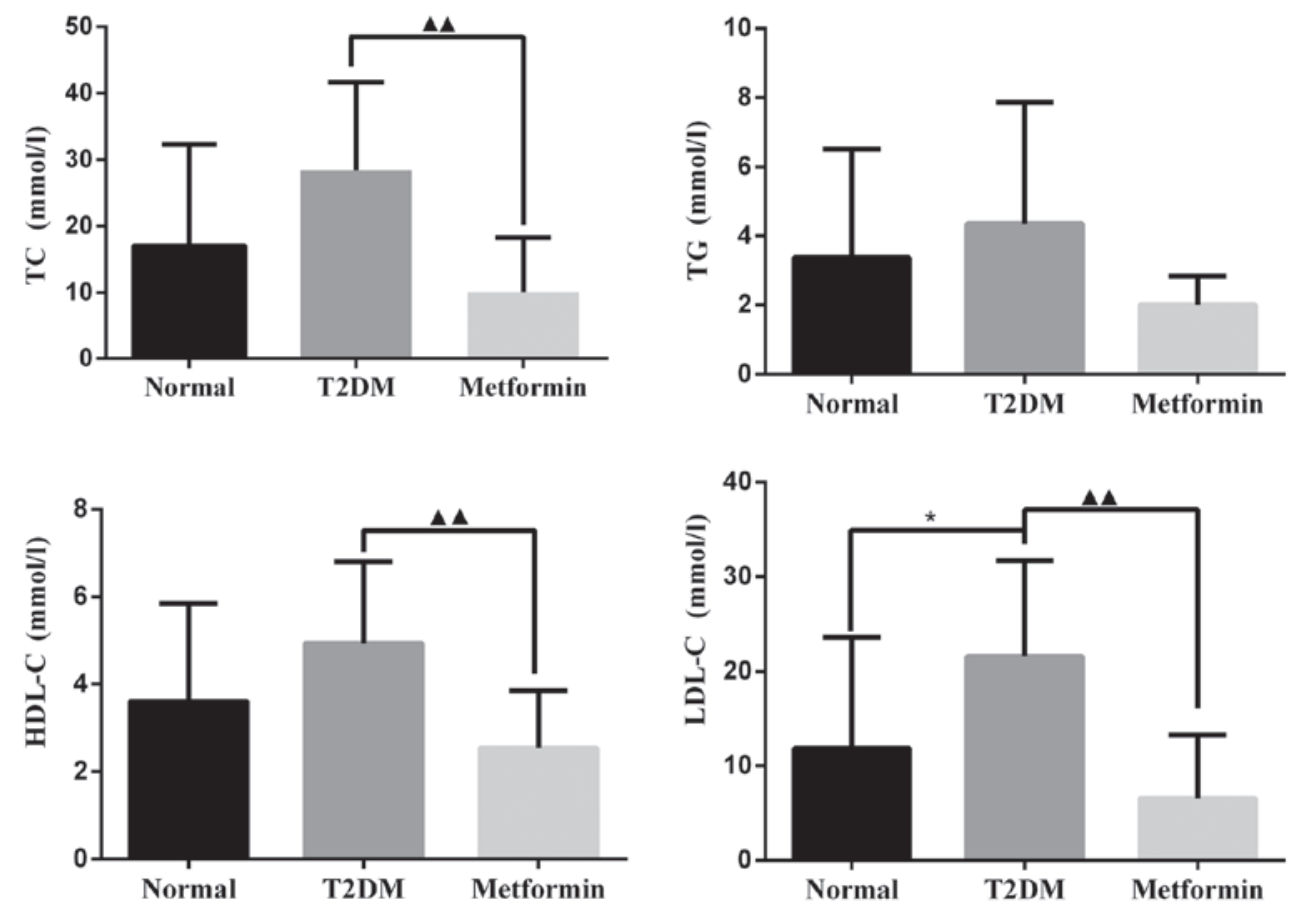

Figure 2. Effects of metformin on biochemical parameters in rats with T2DM. Data are presented as the means \pm standard deviation. "P $<0.05$ the T2DM group vs. the normal group; ${ }^{\wedge} \mathrm{P}<0.01$ the T2DM group vs. the metformin group. HDL-C, high-density lipoprotein cholesterol; LDL-C, low-density lipoprotein cholesterol; T2DM, type 2 diabetes mellitus; TC, total cholesterol; TG, triglycerides.

levels exhibited no difference between the T2DM and metformin groups $(\mathrm{P}>0.05)$. These results indicated that metformin had no effect on serum insulin secretion in T2DM rats under the present experimental conditions. Liver weight and hepatic index were also measured; the results suggested that metformin exerted a protective effect on the liver (Fig. 1D and 1E). In addition, the euglycemic agent metformin had no effect on serum insulin secretion; however, it did improve the insulin sensitivity index, thus suggesting that metformin may enhance insulin sensitivity in the liver (Fig. 1F). These findings also indicated that the T2DM model generated in the present study met the experimental requirements.

Effects of metformin on metabolic and biochemical parameters in rats with T2DM. Rats in the T2DM group exhibited a significant increase in food intake compared with in the normal group $(\mathrm{P}<0.05)$. In addition, body weight was increased in the normal group $(\mathrm{P}<0.01)$, but was decreased in the T2DM group, in spite of the increase in food intake. These results were consistent with the pathological features of the rats in the T2DM group. Metformin did not significantly improve food intake and body weight compared with in the T2DM group ( $\mathrm{P}>0.05$; Table I). Water intake and urine weight were significantly increased in the T2DM rats compared with in the normal rats throughout the treatment period (Table II). Conversely, metformin significantly reduced water intake and urine weight from week $7(\mathrm{P}<0.05)$ and week $5(\mathrm{P}<0.05)$, respectively. These findings suggested that low water intake may result in reduced urine weight.

As shown in Fig. 2, TC, TG and HDL-C were markedly increased in the T2DM group; however, there was no 
Table III. Pathways associated with the gene expression profiles of metformin-treated rat livers, as determined by KEGG analysis.

\begin{tabular}{|c|c|c|c|}
\hline No. & Pathway ID & KEGG pathway & P-value \\
\hline 1 & ko04370 & VEGF signaling pathway & $<0.001$ \\
\hline 2 & ko04141 & Protein processing in endoplasmic reticulum & $<0.001$ \\
\hline 3 & ko04144 & Endocytosis & $<0.001$ \\
\hline 4 & ko01100 & Metabolic pathways & $<0.001$ \\
\hline 5 & ko02010 & $\mathrm{ABC}$ transporters & $<0.01$ \\
\hline 6 & ko04912 & GnRH signaling pathway & $<0.01$ \\
\hline 7 & ko04310 & Wnt signaling pathway & $<0.01$ \\
\hline 8 & ko04650 & Natural killer cell-mediated cytotoxicity & $<0.01$ \\
\hline 9 & ko04010 & MAPK signaling pathway & $<0.01$ \\
\hline 10 & ko04975 & Fat digestion and absorption & $<0.05$ \\
\hline 11 & ko03040 & Spliceosome & $<0.05$ \\
\hline 12 & ko04330 & Notch signaling pathway & $<0.05$ \\
\hline 13 & ko00980 & Metabolism of xenobiotics by cytochrome P450 & $<0.05$ \\
\hline 14 & ko03022 & Basal transcription factors & $<0.05$ \\
\hline 15 & ko00982 & Drug metabolism - cytochrome P450 & $<0.05$ \\
\hline 16 & ko04070 & Phosphatidylinositol signaling system & $<0.05$ \\
\hline 17 & ko00190 & Oxidative phosphorylation & $<0.05$ \\
\hline 18 & ko00500 & Starch and sucrose metabolism & $<0.05$ \\
\hline 19 & ko03010 & Ribosome & $<0.05$ \\
\hline
\end{tabular}

KEGG, Kyoto Encyclopedia of Genes and Genomes.

significant difference when compared with the control group. LDL-C levels were significantly increased in the T2DM group compared with in the control group $(\mathrm{P}<0.05)$. After 11 weeks of treatment with metformin, TC, HDL-C and LDL-C levels were significantly decreased compared with in the T2DM group $(\mathrm{P}<0.01)$. There was no significant difference in $\mathrm{TG}$ levels between the metformin and T2DM groups $(\mathrm{P}=0.064)$; however, metformin did slightly reduce TG levels under the present experimental conditions.

Gene expression profiles in liver tissues frommetformin-treated T2DM rats. Microarray experiments were performed three times in each experimental group to obtain accurate results. DEGs associated with the onset of T2DM in the livers of metformin-treated rats were determined. Analysis of the microarray data demonstrated that metformin had a significant effect on gene expression in hepatic tissues. The expression levels of 1,021 genes were altered >1.5-fold; 592 genes were upregulated and 429 genes were downregulated in T2DM rats compared with the normal group. Metformin administration significantly altered the expression of 431 genes $>1.5$-fold; 238 genes were upregulated and 193 genes were downregulated. Evaluation of these genes demonstrated that metformin treatment had a considerable impact on various biological processes, molecular functions and cellular components in the liver. The primary biological processes affected by metformin treatment included the G-protein coupled receptor signal pathway, regulation of transcription, ion transport, response to drugs and signal transduction (Fig. 3). The molecular function ontologies most affected included metal ion binding, molecular function, protein binding, ATP binding and nucleotide binding receptor activity. The cellular components associated with metformin treatment were cytoplasm, nucleus, membrane, mitochondrion, intracellular part and cytosol. A total of 19 pathways were revealed to be significantly altered by metformin $(\mathrm{P}<0.05$; Table III). The genes that exhibited altered expression upon metformin treatment were categorized according to pathway analysis, the associated pathways included protein processing in endoplasmic reticulum, metabolic pathways, endocytosis, ABC transporters, GnRH signaling pathway, WNT signaling pathway, fat digestion and absorption, metabolism of xenobiotics by cytochrome P450, and starch and sucrose metabolism.

Protein expression profiles in liver tissues from metformin-treated rats with T2DM. All MS/MS spectra were processed using Mascot software 2.3.02. As shown in Fig. 4A, iTRAQ analysis of the IPI_rat V 3.87 proteome detected 5,954 unique peptides in the database $(39,925$ sequences), resulting in 634 differential protein ( $>1.2$-fold) hits in Mascot. As shown in Fig. 4B, 232 differential proteins were identified between the metformin and normal groups, of which 148 proteins were upregulated and 84 proteins were downregulated. Furthermore, 402 differential proteins were identified between the metformin and T2DM groups, of which 209 proteins were upregulated and 193 proteins were downregulated. As presented in Table IV, 64 upregulated proteins and 31 downregulated proteins were identified when comparing both the metformin and normal groups, and the metformin and T2DM groups. Of the upregulated proteins in the metformin group, 3/148 were involved in translation, 1/148 was involved in transcription, 4/148 were signal transduction 
Table IV. Upregulated and downregulated proteins identified when comparing both the metformin and normal groups, and the metformin and T2DM groups.

CERU, CP3A1, CP3AI, IGG2A, HPRT, REEP6, ANXA3,

GCST, LDHD, PDK2, CP7A1, SNTB2, KNT1, PSD12, HACD3, K0664, H17B6, CAH5A, APOC1, ACSF2, THIKB, SRSF2, ACTN1, PLCB, HSPB1, BIEA, ADH4, S22AI, MGLL, ADH6, MET7B, KCRB, VNN1, CP3A9, FABP4, EST1, CP2C7, MYH10, APOB, LEG3, HXK3, XPP2, S27A2, CRP, LASP1, CX6B1, EST1C, KPYM, MOSC2, PSB10, CP4V2, HPPD, UD2B4, GMFB, TOM22, FLOT1, CLUS, CP255, CO1A1, PP2AA, HRG, IIGP1, HVM57, EST5
DCPS, GLGB, PPM1A, FAS, AAAD, CP4F6, DHCR7, FPPS, DHB13, DYR, TYPH, TRAM1, MCEE, GRHPR, NMRL1, KAD4, UD16, AT2L1, CISD1, NDUA7, TXTP, ADO, HBB1, ACBP, UK114, SYCC, CSAD, ASGR2, NTF2, GSH1, NDUAA

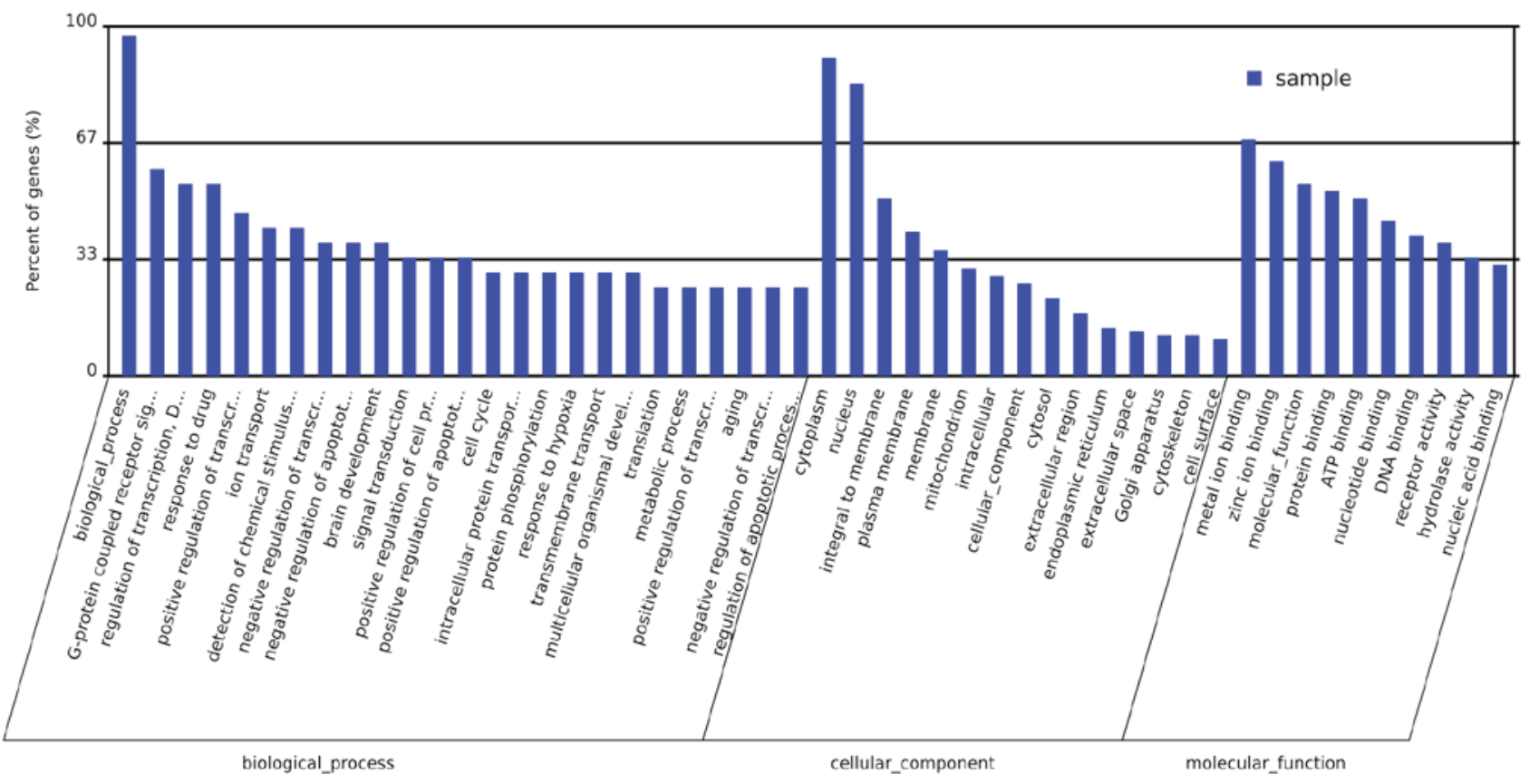

Figure 3. Gene Ontology analysis of the differentially expressed genes affected by metformin in liver tissues.

proteins, $12 / 148$ were secondary metabolite biosynthesis proteins, $16 / 148$ were post-translational modification proteins, $1 / 148$ was a nucleotide transport and metabolism protein, 10/148 were lipid transport and metabolism proteins, 1/148 was a secretion and vesicular transport protein, 13/148 were general function proteins, $2 / 148$ were inorganic ion transport and metabolism proteins, $8 / 148$ were energy production and conversion proteins, $3 / 148$ were cytoskeleton proteins, $5 / 148$ were carbohydrate transport and metabolism proteins, 11/148 were amino acid transport and metabolism proteins, $1 / 148$ was a membrane protein, and others were listed as unknown proteins. Of the downregulated proteins in the metformin group, 4/84 were translation proteins, 1/84 was a signal transduction protein, $5 / 84$ were secondary metabolite biosynthesis proteins, 4/84 were post-translational modification proteins, $4 / 84$ were nucleotide transport and metabolism proteins, $8 / 84$ were lipid transport and metabolism proteins, 2/84 were secretion and vesicular transport proteins, 6/84 were general function proteins, $4 / 84$ were energy production and conversion proteins, 1/84 was a defense protein, 1/84 was a cytoskeleton protein, 2/84 were coenzyme transport and metabolism proteins, $1 / 84$ was a membrane protein, 1/84 was a cell division protein, 5/84 were carbohydrate transport and metabolism proteins, 7/84 were amino acid transport and metabolism proteins, and others were listed as unknown proteins. The associated cellular components, as determined by Gene Ontology (GO) analysis of the proteins, were cell (21.84\%), cell part (21.84\%), organelle (18.37\%) and organelle part (13.55\%) (Fig. 5A). The proteins could also be categorized into numerous biological processes, including cellular process (15\%), metabolic process $(13.42 \%)$ and biological regulation (8.39\%) (Fig. 5B). The major molecular functions of the proteins, as obtained by $\mathrm{GO}$ analysis, were binding (46.27\%) and catalytic activity (32.13\%) (Fig. 5C). The results of KEGG analysis indicated that 10 pathways were significantly affected by metformin, with a cut-off value of $\mathrm{P}<0.05$. The pathway analysis was used to categorize proteins with altered expression upon metformin treatment; 
Table V. Pathways associated with the differential proteins in metformin-treated rat livers, as determined by KEGG analysis.

\begin{tabular}{clll}
\hline No. & Pathway ID & \multicolumn{1}{c}{ KEGG pathway } & P-value \\
\hline 1 & ko00830 & Retinol metabolism & $<0.00001$ \\
2 & ko00140 & Steroid hormone biosynthesis & $<0.00001$ \\
3 & ko04976 & Drug metabolism-other enzymes & $<0.00001$ \\
4 & ko01100 & Bile secretion & $<0.00001$ \\
5 & ko00980 & Metabolic pathways & $<0.0001$ \\
6 & ko00598 & Linoleic acid metabolism & $<0.001$ \\
7 & ko00591 & Arachidonic acid metabolism & $<0.001$ \\
8 & ko03320 & Drug metabolism-cytochrome P450 & $<0.001$ \\
9 & & Metabolism of xenobiotics by cytochrome P450 & $<0.001$ \\
10 & & PPAR signaling pathway & $<0.001$
\end{tabular}

KEGG, Kyoto Encyclopedia of Genes and Genomes.
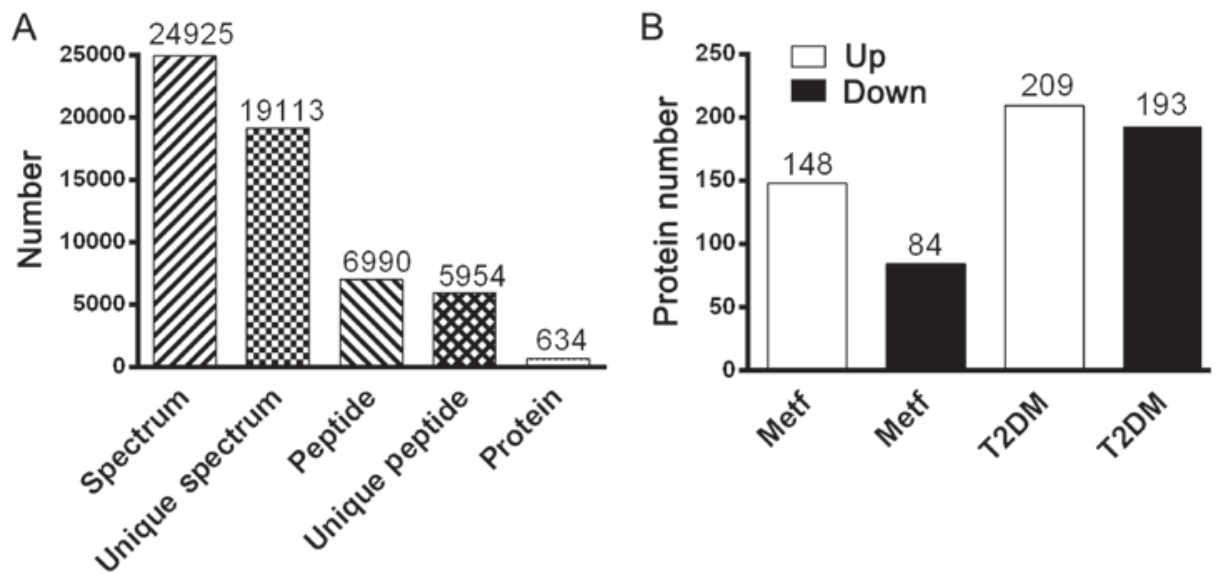

Figure 4. Differential protein expression in liver tissues from metformin-treated rats. (A) Results of isobaric tags for relative and absolute quantitation analysis; (B) differentially expressed proteins in the T2DM and metformin treatment groups. T2DM, type 2 diabetes mellitus.

significant pathways included retinol metabolism, steroid hormone biosynthesis, drug metabolism, bile secretion, linoleic acid metabolism, arachidonic acid metabolism, metabolism of xenobiotics by cytochrome P450 and PPAR signaling pathway (Table V).

Potential therapeutic target genes, screened for with microarray and $i T R A Q$ analysis. A 1.2-fold change in protein expression and 1.5-fold alteration in gene expression served as benchmarks for significant physiological changes; 18 genes were reported to exhibit the same trend in microarray and iTRAQ analyses in the T2DM group, with a cut-off value of $\mathrm{P}<0.05$. Among these genes, 12 genes were upregulated and 6 genes were downregulated (Table VI). Further analysis demonstrated that 7 genes exhibited the same trend in microarray and iTRAQ analyses in the metformin group, as shown in Table VII. Among these genes, ethanolamine-phosphate phospho-lyase (LOC687071) was downregulated, whereas Cyp7a1, Ces1C, solute carrier family 27 member 2 (Slc27a2), ceruloplasmin $(\mathrm{Cp})$, pyruvate kinase $\mathrm{M}(\mathrm{PKM})$ and clustered mitochondria homolog (Cluh) were upregulated. As shown in Tables VI and VII, Ces1C and Cyp7a1 were differentially altered in both the T2DM and metformin groups, indicating that these two genes/proteins were altered in T2DM and metformin groups. Therefore, it may be hypothesized that Cyp7a1 and Ces1C serve important roles in diabetes and may be primary candidate targets for metformin. Furthermore, Slc27a2, Cp, PKM, Cluh and LOC687071 may be worthy of further study under certain conditions. The $\log _{2}$ (DM/NOR) value for Ces1C in the microarray analysis was -0.58 , thus indicating that Ces1C expression was increased in the normal group compared with in the T2DM group. The $\log _{2}$ (DM/MET) value for Ces1C in the microarray analysis was -0.63 , thus suggesting that Ces1C expression was increased in the metformin group compared with in the T2DM group. These findings indicated that Ces1C expression was increased in the metformin group. The iTRAQ analysis demonstrated that Ces1C protein levels were highest in the normal group and lowest in the T2DM group. With regards to the Cyp7a1 gene, the results of microarray and iTRAQ analyses were similar; the expression was highest in the normal group and lowest in the T2DM group among the three groups.

To determine the mRNA and protein expression levels, qPCR and western blot analysis were performed on selected potential therapeutic target genes, identified using microarray 

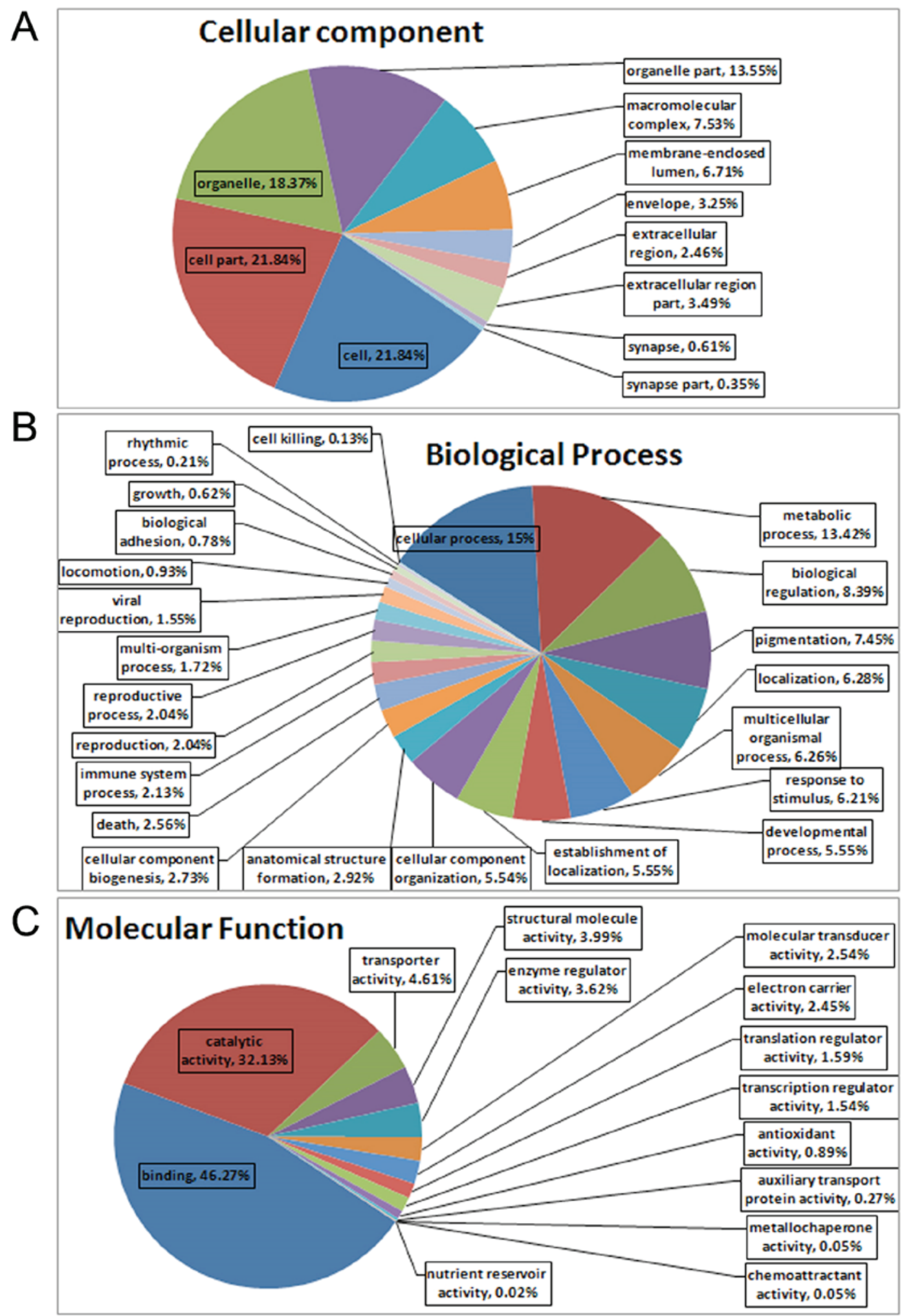

Figure 5. Analysis of differential proteins in liver tissues from metformin-treated rats based on (A) cellular component, (B) biological process and (C) molecular function.

and iTRAQ analyses (Fig. 6). The mRNA expression levels of Ces1C were significantly altered $(\mathrm{P}<0.01)$; Ces1C expression was increased in rat liver tissues obtained from the metformin group; however, no difference was detected between the normal and T2DM groups (Fig. 6A). The protein expression levels of Ces1C are presented in Fig. 6B.
Although no significant differences were detected among the groups, a similar trend to iTRAQ analysis was determined. qPCR and western blot analysis confirmed the results of the microarray and iTRAQ analyses. The expression levels of Cyp7a1 are shown in Fig. 6C and D. qPCR demonstrated that Cyp7a1 expression was significantly increased in the 
A
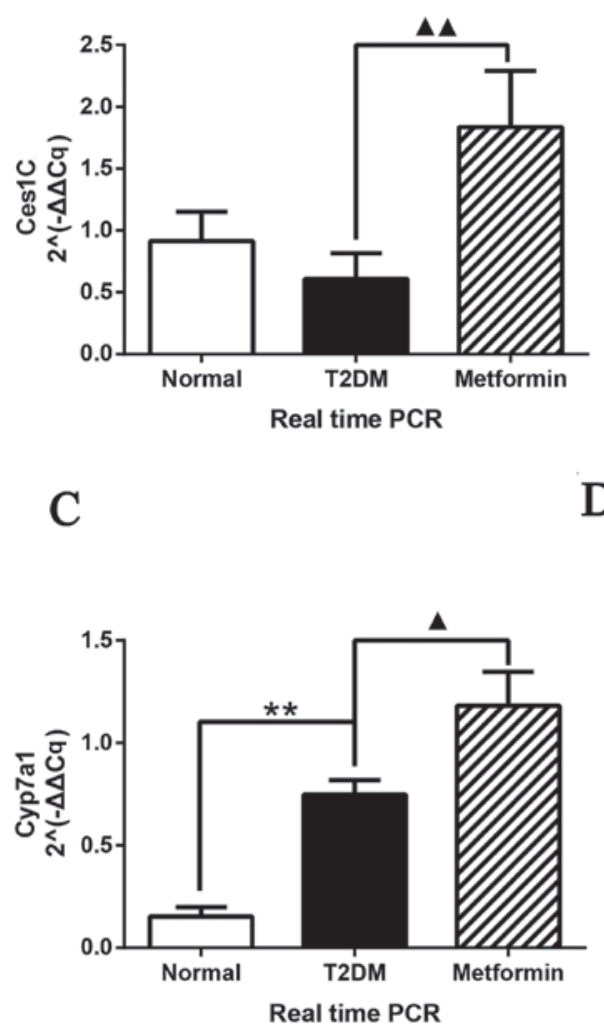

B
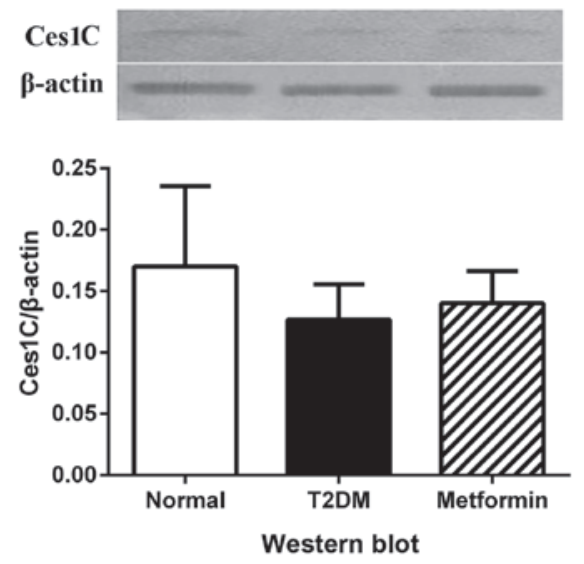

D
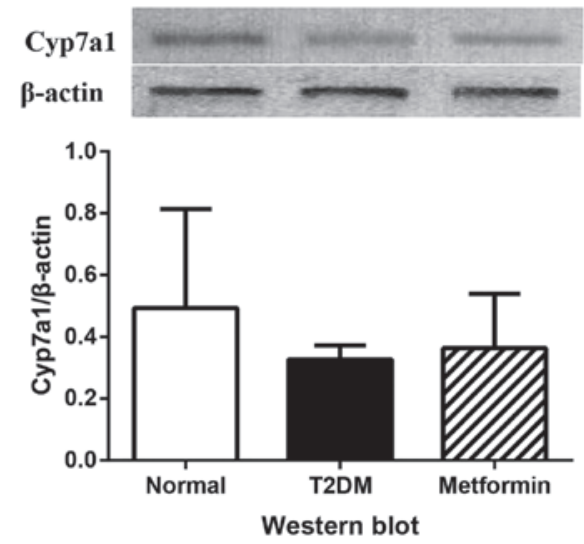

Figure 6. Cyp7a1 and Ces1C expression in Sprague-Dawley rat liver tissues. (A) qPCR analysis of Ces1C gene expression and (B) western blot analysis of Ces1C protein expression. (C) qPCR analysis of Cyp7a1 gene expression and (D) western blot analysis of Cyp7a1 protein expression. Data are presented as the means \pm standard deviation. ${ }^{* *} \mathrm{P}<0.01$ the T2DM group vs. the control group; ${ }^{\wedge} \mathrm{P}<0.05$ and ${ }^{\wedge} \mathrm{P}<0.01$ the T2DM group vs. the metformin group. Ces1C, carboxylesterase 1C subunit; Cyp7a1, cholesterol 7 $\alpha$-hydroxylyase; qPCR, quantitive polymerase chain reaction ; T2DM, type 2 diabetes mellitus.

T2DM group; this finding was inconsistent with the findings of the microarray analysis. However, metformin significantly increased Cyp7a1 expression, which was consistent with the findings of the microarray analysis. Western blot analysis exhibited a similar trend to the results of the iTRAQ analysis with regards to Cyp7a1 protein expression; the protein expression levels of Cyp7a1 were highest in the normal group and lowest in the T2DM group; however, these were findings were not significantly different.

\section{Discussion}

T2DM is a complex chronic metabolic disease, which is associated with microvascular and macrovascular complications. A great deal of research has focused on elucidating the pathophysiology of T2DM over the past 50 years $(20,21)$; however, the mechanisms underlying T2DM remain poorly understood. It is, however, now well known that insulin resistance or low insulin secretion is a major mechanism (22). In general, normoglycemia is maintained by the balance between insulin secretion and the efficacy of insulin action. Blood glucose levels increase when this balance is disrupted, which leads to structural destruction and functional visceral disorder. Serious, long-term hyperglycemia can be fatal; therefore, decreasing high blood glucose levels is considered a direct and efficient therapeutic strategy (23).
The present study established a rat model of T2DM using STZ, according to methods described by Reed et al (24). STZ-induced T2DM is a typical T2DM rat model, which ensured the veracity of the present experiments. STZ is a DNA alkylation reagent, which selectivity destructs pancreatic $\beta$ cells, thus resulting in hyperglycemia. In the present study, obvious weight losses were detected in the T2DM group compared with in the metformin group in the first week, which may be because of individual differences, fasting (hypoglycemia) resistance difference and unadaptable under conditions of hyperglycemia. In the present study, diabetic rats exhibited polydipsia and polyuria, thus suggesting that increased water intake results in increased urine output. The present data demonstrated that metformin improved body weight and urine weight but did not return it to normal levels. Numerous studies have reported that increased HDL levels are an independent risk factor for the development of cardiovascular disease, and decreases in LDL can significantly reduce the risk of cardiovascular disease and mortality in patients with T2DM $(25,26)$. In the present study, HDL-C and LDL-C were significantly downregulated in the metformin-treated group, which indicated that metformin exerted protective effects against cardiovascular disease in T2DM rats. HbA1c is an approximation of an individual's average blood glucose levels for the prior 2-3 months, and is currently considered the gold standard for monitoring glycemic control. In the present study, 
Table VII. mRNA and protein expression levels in metformin-treated rats.

\begin{tabular}{|c|c|c|c|c|c|}
\hline \multirow[b]{2}{*}{ Gene symbol } & \multicolumn{2}{|c|}{ Transcriptomics } & \multicolumn{2}{|c|}{ Proteomics } & \multirow[b]{2}{*}{ Up or down } \\
\hline & $\log _{2}(\mathrm{DM} / \mathrm{MET})$ & $\log _{2}(\mathrm{DM} / \mathrm{NOR})$ & DM/MET & $\mathrm{DM} / \mathrm{NOR}$ & \\
\hline Cyp7a1 & -0.60 & -1.52 & 0.56 & 0.361 & Up \\
\hline Ces1C & -0.63 & -0.58 & 0.636 & 0.496 & Up \\
\hline Slc27a2 & -0.92 & -1.80 & 0.764 & 0.517 & Up \\
\hline $\mathrm{Cp}$ & -1.06 & -1.15 & 0.788 & 0.648 & Up \\
\hline PKM & -0.54 & -0.99 & 0.756 & 0.655 & Up \\
\hline Cluh & -0.30 & -0.45 & 0.831 & 0.758 & $\mathrm{Up}$ \\
\hline LOC687071 & 0.55 & 2.88 & 1.477 & 1.735 & Down \\
\hline
\end{tabular}

Ces1C, carboxylesterase 1C subunit; Cyp7a1, cholesterol 7 $\alpha$-hydrolyse; Cluh, clustered mitochondria homolog; Cp, ceruloplasmin ; DM, type 2 diabetes mellitus; LOC687071, ethanolamine-phosphate phospho-lyase; MET, metformin; NOR, normal; PKM, pyruvate kinase M; Slc27a2, solute carrier family 27 member 2 .

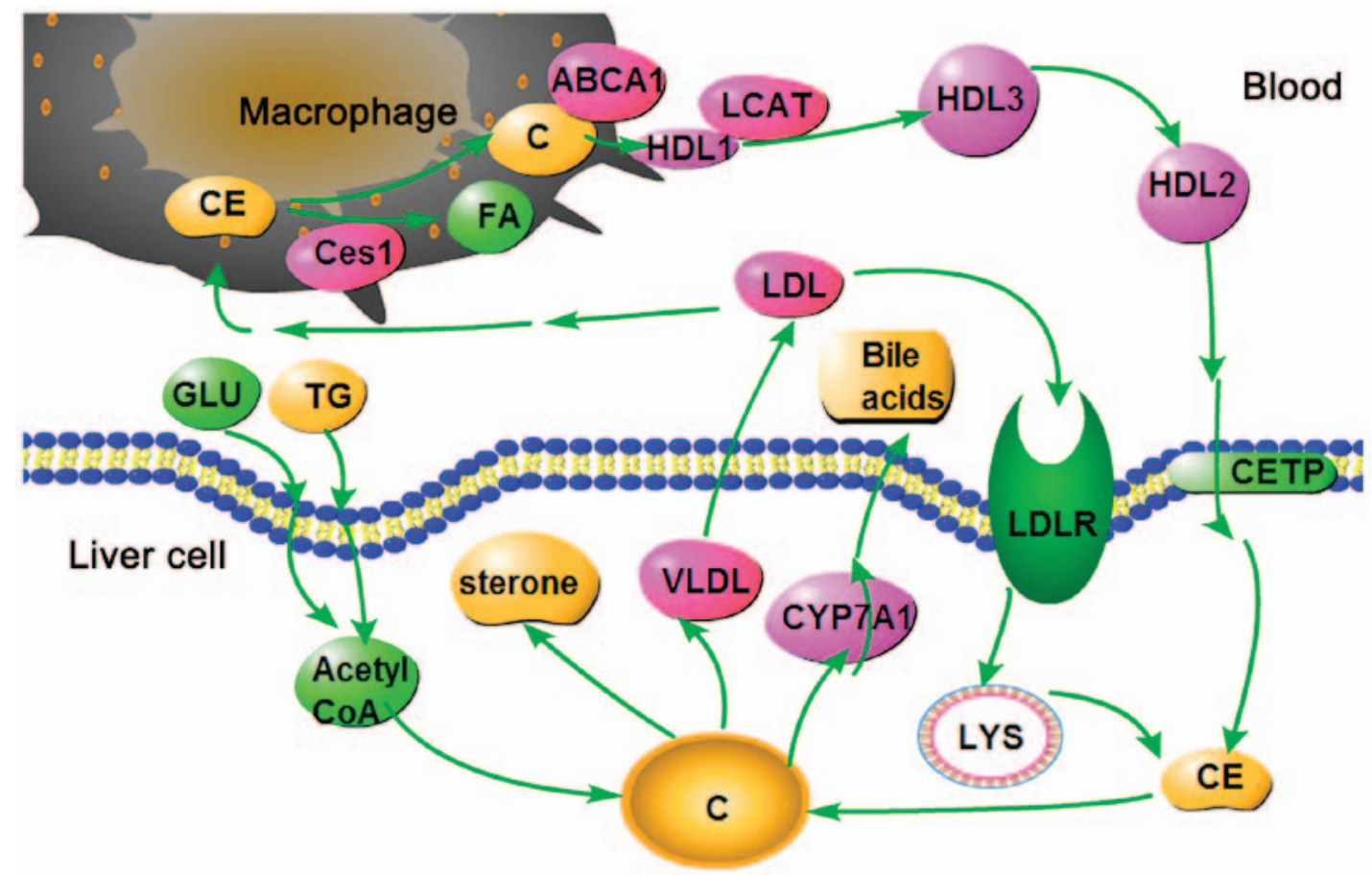

Figure 7. Cholesterol metabolism pathway in the liver. ABCA1, ATP-binding cassette ABC transporter; C, cholesterol; CE, cholesteryl ester; Ces1, carboxylesterase 1C subunit; CETP, cholesteryl ester transfer protein; CYP7A1, cholesterol 7 $\alpha$-hydroxylyase; FA, fatty acid; GLU, glucose; HDL, high-density lipoprotein; LCAT, lecithin cholesterol acyltransferase; LDL, low-density lipoprotein; LYS, lysosome; TG, triglycerides; VLDL, very low-density lipoprotein.

rats were treated with metformin for $\sim 3$ months, which was enough to reduce HbA1c levels in a similar trend to FBG (27). The T2DM model was evaluated by measuring FPG, HbA1c, plasma insulin, liver index and insulin sensitivity index, the results of which confirmed that the T2DM model had been successfully generated.

FPG and HbA1c were significantly reduced following metformin treatment compared with in the T2DM group. Subsequently, gene chip and iTRAQ analyses were performed to identify the significant DEGs and proteins in order to screen the key genes in the liver. Ces1C and Cyp7al were downregulated in T2DM rats and were upregulated in metformin-treated rats at mRNA and protein levels; therefore, they were regarded as potential therapeutic target genes associated with metformin intervention in the liver tissues of rats with T2DM. In addition, KEGG and GO analysis suggested that the DEGS and proteins were associated with the following pathways: Lipid metabolism, steroid hormone biosynthesis, bile secretion, arachidonic acid, ABC transporters, fat digestion and absorption, PPAR signaling pathway and metabolism of xenobiotics by cytochrome $\mathrm{P} 450$.

The Ces1C gene encodes a subunit of carboxylesterase 1, also known as cholesteryl ester hydrolase, which has been demonstrated to mediate hydrolysis in adipose tissues (28). 
Table VI. mRNA and protein expression levels in DM model rats.

\begin{tabular}{|c|c|c|c|c|}
\hline \multirow[b]{2}{*}{$\begin{array}{l}\text { Gene } \\
\text { symbol }\end{array}$} & \multicolumn{2}{|c|}{ Transcriptomics } & \multicolumn{2}{|c|}{ Proteomics } \\
\hline & $\begin{array}{c}\log _{2} \\
\text { (DM/NOR) }\end{array}$ & $\begin{array}{l}\text { Up or } \\
\text { down }\end{array}$ & $\mathrm{DM} / \mathrm{NOR}$ & $\begin{array}{l}\text { Up or } \\
\text { down }\end{array}$ \\
\hline Ces1C & -0.58 & Down & 0.496 & Down \\
\hline Fgb & -0.59 & Down & 0.821 & Down \\
\hline Cyp7a1 & -1.52 & Down & 0.361 & Down \\
\hline Tfre & -2.33 & Down & 0.637 & Down \\
\hline Banf1 & -0.64 & Down & 0.644 & Down \\
\hline Psmd6 & -1.63 & Down & 0.672 & Down \\
\hline Gsta2 & 0.41 & Up & 1.289 & Up \\
\hline Tst & 0.49 & Up & 1.256 & Up \\
\hline Rpl10 & 0.85 & Up & 1.884 & $\mathrm{Up}$ \\
\hline Ugt1a6 & 0.34 & Up & 1.241 & Up \\
\hline Rars & 1.86 & Up & 1.222 & Up \\
\hline Fam120a & 1.24 & Up & 1.266 & Up \\
\hline Actr1a & 0.70 & Up & 1.219 & Up \\
\hline Tram1 & 0.76 & Up & 1.529 & Up \\
\hline Rpl23a & 0.39 & Up & 1.455 & Up \\
\hline Rps271 & 0.54 & Up & 1.465 & Up \\
\hline LOC687071 & 2.88 & Up & 1.735 & Up \\
\hline Hdhd3 & 1.71 & Up & 1.265 & Up \\
\hline
\end{tabular}

Actr1a, ARP1 actin-related protein 1 homolog A, centractin $\alpha$; Banf1, barrier to autointegration factor 1; Ces1C, carboxylesterase 1C subunit; Cyp7a1, cholesterol $7 \alpha$-hydroxylyase; DM, type 2 diabetes mellitus; Fam120a, family with sequence similarity 120A; Fgb, fibrinogen $\beta$ chain; Gsta2, glutathione S-transferase $\alpha 2$; Hdhd3, haloacid dehalogenase-like hydrolase domain containing 3; LOC687071, ethanolamine-phosphate phospho-lyase; NOR, normal; Psmd6, proteasome 26S subunit, non-ATPase 6; Tfrc, transferrin receptor; Rars, arginyl-tRNA synthetase; Rpl10, ribosomal protein L10; Rpl23a, ribosomal protein L23a; Rps271, ribosomal protein S27-like; Tram1, translocation-associated membrane protein 1; Tst, thiosulfate sulfurtransferase; Ugt1a6, UDP glucuronosyltransferase family 1 member A6.

In a previous study, Ces1 was reported to be upregulated in obese subjects, and was revealed to have a close association with transport and catabolism of cholesteryl ester and free fatty acids $(29,30)$. The mutation and variation of the Ces1 gene may result in metabolic disorders and obesity-associated diseases, including diabetes mellitus and hypercholesterolemia. Cyp7a1 belongs to the cytochrome P450 enzyme family, which is exclusively expressed in the liver, and is a key enzyme in cholesterol catabolism to bile acids that is important for maintaining appropriate cholesterol levels. Since Cyp7a1 catalyzes the initial and rate-limiting step in the neutral synthetic pathway of bile acids from cholesterol, it is considered an essential enzyme in cholesterol homeostasis. In addition, Cyp7a1 gene expression is regulated by oxysterols, bile acids, hormones, nutrients and cytokines (31). In response to a high-fat diet, Cyp7a1 expression has been reported to be induced (32). A previous study demonstrated that Cyp7a1 serves a crucial role in maintaining whole-body lipid levels, glucose levels and energy homeostasis. Therefore, Cyp7a1 may be a potential therapeutic target for the treatment of metabolic disorders, such as fatty liver diseases, obesity and diabetes in humans (33). However, in the present study, the results of western blotting demonstrated that the protein expression levels of Ces1C and Cyp7a1 were not consistent with the mRNA alterations. Ces1C is a drug-metabolizing enzyme, which is synthesized and secreted in the liver, and the mRNA expression and activity of Ces1C exhibit significant individual differences $(34,35)$. Single nucleotide polymorphisms have an important effect on the expression and/or activity of drug-metabolizing enzymes, which may explain the individual differences in protein response in the present study. In addition, the inconsistencies in mRNA and protein expression of Ces1C may be caused by upstream regulation and epigenetic alterations. Bile acids are the end products of cholesterol metabolism, which have an important role in cholesterol homeostasis. Upregulated Cyp7a1 may lead to higher levels of bile acids $(35,37)$. Subsequently, increased bile acid levels may inhibit the catabolism of cholesterol via a negative feedback mechanism, thus suppressing Cyp7a1 expression and function by promoting the hepatic and intestinal farnesoid $\mathrm{X}$ receptor signal pathways (38). It may be hypothesized that elevated bile acids suppress the protein expression levels of Cyp7a1 in the present study, hence the inconsistency. However, the effects of metformin on bile acids and Cyp7a1 require further studies

As shown in Fig. 7, high glucose and fat levels induce an increase in acetyl coenzyme A (Acetyl-CoA). Since all carbon atoms in cholesterol are supplied by Acetyl-CoA, increased Acetyl-CoA content may increase cholesterol synthesis. Cholesterol homeostasis is maintained by the selective transfer of cholesterol from the peripheral cell to HDL, from HDL to the liver for bile acid synthesis or disposal via bile, and finally to steroidogenic cells for hormone synthesis. High Cyp7a1 expression may result in the rapid conversion of cholesterol to bile acids and bile salts in the liver. Furthermore, the oversupply of cholesterol may be transferred into the plasma via very LDL and LDL. LDL may then enter LDL receptor-containing cells via endocytosis. Cholesteryl ester is thus released and hydrolyzed to fatty acids and cholesterol by lysosomal enzymes. In addition, LDL may be engulfed by macrophages via a scavenger receptor. Cholesteryl ester is thus released and hydrolyzed to fatty acids and cholesterol by carboxyl esterase 1 . The efflux of cholesterol from macrophages to HDL is mediated by ATP-binding cassette ABC transporter (39). In the plasma, cholesterol is taken up by HDL and immediately esterified by the plasma enzyme lecithin-cholesterol acyltransferase. Cholesteryl ester is then transferred to the liver via reverse cholesterol transport.

The present study demonstrated that Cyp7a1 and Ces1C are upregulated by metformin. These findings indicated that cholesterol was removed from the body via rapid conversion to bile acids and hydrolysis into the cholesteryl ester form. Finally, cholesterol levels were decreased.

It has previously been reported that metformin may induce the activation of AMPK. Furthermore, activation of AMPK may inhibit fatty acid and cholesterol synthesis (4). Although AMPK stimulation was not detected in the present study, the present results revealed that metformin significantly upregu- 
lated the expression of two genes associated with cholesterol metabolism; therefore, stimulation of cholesterol breakdown, instead of synthesis, would be expected, which is the outcome of AMPK activation. Furthermore, the present study demonstrated that metformin upregulated the expression of $\mathrm{Cp}$, which is an enzyme combined with copper (40). Logie et al (41) previously indicated that the cellular effects of metformin depended on metal-binding properties, particularly on the copper ion. In a sense, the present study is therefore consistent with previous studies regarding the antidiabetic mechanism of metformin.

The other DEGs discovered in the present study were involved in carbohydrate metabolism, lipid metabolism and protein transport. Family with sequence similarity 120A, which belongs to the peroxisome proliferator-activated receptors- $\gamma$ family, and Slc27a2, also known as long-chain-fatty-acid-CoA ligase 1 , were previously reported to be associated with lipid metabolism and diabetes mellitus $(42,43)$. PKM is the third key enzyme in glycolysis, which is inhibited in patients with diabetes mellitus (44). In addition, translocation-associated membrane protein 1 inhibition has been revealed to decrease protein transport in defective insulin secretion (45). Therefore, we aim to investigate these other DEGs in a follow-up study.

In conclusion, the present study demonstrated that metformin is a multitarget antidiabetic drug, which can affect the expression of numerous hepatic genes involved in several metabolic pathways, particularly those associated with lipid and cholesterol metabolism. In addition, Ces1C and Cyp7a1 were differentially expressed in the T2DM and metformin groups. It is expected that these findings may be useful to aid understanding of the mechanism underlying the antidiabetic action of metformin. The present study may also offer a novel approach to drug discovery based on comprehensive research and assessment.

\section{Acknowledgements}

The authors would like to thank Professor Lisheng Chu, Dr Qiyang Shou and Mr. Yongle Yang (Zhejiang Chinese Medical University) for helpful discussions.

\section{Funding}

The present study was supported by grants from the Project of National Great New Drug Research and Development (grant no. 2012ZX09503001-001) and the National Natural Science Foundation Project (grant no. 81374023). The study was also supported by the Traditional Chinese Medicine Open Funds of Zhejiang Chinese Medical University (grant no. 752223A00201/005/019).

\section{Availability of data and materials}

All data generated or analyzed during this study are included in this published article.

\section{Authors' contributions}

YC, YW, YY, ZX and CL conceived and designed the experiments and performed the experiments. JT, ZL and XZ analyzed the data. YC wrote the manuscript. All authors read and approved the final manuscript.

\section{Ethics approval and consent to participate}

The present study was approved by the Laboratory Animal Management and Welfare Ethics Review Committee of Zhejiang Chinese Medical University (permit no. ZSLL-2013-48).

\section{Consent for publication}

Not applicable.

\section{Competing interests}

The authors declare that they have no competing interests.

\section{References}

1. Wei S, Zhang M, Yu Y, Lan X, Yao F, Yan X, Chen L and Hatch GM: Berberine attenuates development of the hepatic gluconeogenesis and lipid metabolism disorder in type 2 diabetic mice and in palmitate-incubated HepG2 cells through suppression of the HNF-4 $\alpha$ miR122 pathway. PLoS One 11: e0152097, 2016.

2. Reboldi G, Gentile G, Angeli F, Ambrosio G, Mancia G and Verdecchia P: Effects of intensive blood pressure reduction on myocardial infarction and stroke in diabetes: A meta-analysis in 73,913 patients. J Hypertens 29: 1253-1269, 2011

3. Zhang Q, Xiao X, Li M, Li W, Yu M, Zhang H, Ping F, Wang Z and Zheng J: Berberine moderates glucose metabolism through the GnRH-GLP-1 and MAPK pathways in the intestine. BMC Complement Altern Med 14: 188, 2014.

4. Correia S, Carvalho C, Santos MS, Seiça R, Oliveira CR and Moreira PI: Mechanisms of action of metformin in type 2 diabetes and associated complications: An overview. Mini Rev Med Chem 8: 1343-1354, 2008

5. No authors listed: Intensive blood-glucose control with sulphonylureas or insulin compared with conventional treatment and risk of complications in patients with type 2 diabetes (UKPDS 33). UK Prospective Diabetes Study (UKPDS) Group. Lancet 352: 837-853, 1998.

6. No authors listed: Effect of intensive blood-glucose control with metformin on complications in overweight patients with type 2 diabetes (UKPDS 34). UK Prospective Diabetes Study (UKPDS) Group. Lancet 352: 854-865, 1998

7. Tian S, Li Y, Li D, Xu X, Wang J, Zhang Q and Hou T: Modeling compound-target interaction network of traditional Chinese medicines for type II diabetes mellitus: Insight for polypharmacology and drug design. J Chem Inf Model 53: 1787-1803, 2013.

8. Kirpichnikov D, McFarlane SI and Sowers JR: Metformin: An update. Ann Intern Med 137: 25-33, 2002.

9. Bailey CJ and Turner RC: Metformin. N Engl J Med 334: 574-579, 1996.

10. Cusi K and DeFronzo RA: Metformin: A review of its metabolic effects. Diabetes Res 6: 89-131, 1998.

11. Stumvoll M, Nurjhan N, Perriello G, Dailey G and Gerich JE: Metabolic effects of metformin in non-insulin-dependent diabetes mellitus. N Engl J Med 333: 550-554, 1995.

12. Epstein S: Role of metformin in type II diabetes. Cleve Clin J Med 62: 278-279, 1995.

13. Zhou G, Myers R, Li Y, Chen Y, Shen X, Fenyk-Melody J, Wu M, Ventre J, Doebber T, Fujii N, et al: Role of AMP-activated protein kinase in mechanism of metformin action. J Clin Invest 108: $1167-1174,2001$.

14. Shaw RJ, Lamia KA, Vasquez D, Koo SH, Bardeesy N, Depinho RA, Montminy M and Cantley LC: The kinase LKB1 mediates glucose homeostasis in liver and therapeutic effects of metformin. Science 310: 1642-1646, 2005.

15. Kim J, Shon E, Kim CS and Kim JS: Renal podocyte injury in a rat model of type 2 diabetes is prevented by metformin. Exp Diabetes Res 2012: 210821, 2012

16. Hopkins AL: Network pharmacology. Nat Biotechnol 25: 1110-1111, 2007.

17. Hopkins AL: Network pharmacology: The next paradigm in drug discovery. Nat Chem Biol 4: 682-690, 2008.

18. Zhang GB, Li QY, Chen QL and Su SB: Network pharmacology: A new approach for chinese herbal medicine research. Evid Based Complement Alternat Med 2013: 621423-621423, 2013. 
19. Livak KJ and Schmittgen TD: Analysis of relative gene expression data using real-time quantitative PCR and the 2(-Delta Delta C(T)) Method. Methods 25: 402-408, 2001

20. Yang W, Lu J, Weng J, Jia W, Ji L, Xiao J, Shan Z, Liu J, Tian H, Ji Q, et al; China National Diabetes and Metabolic Disorders Study Group: Prevalence of diabetes among men and women in China. N Engl J Med 362: 1090-1101, 2010.

21. Xu Y, Wang L, He J, Bi Y, Li M, Wang T, Wang L, Jiang Y, Dai M, Lu J, et al; 2010 China Noncommunicable Disease Surveillance Group: Prevalence and control of diabetes in Chinese adults. JAMA 310: 948-959, 2013.

22. Stumvoll M, Goldstein BJ and van Haeften TW: Pathogenesis of type 2 diabetes. Endocr Res 32: 19-37, 2007.

23. Hundal RS, Krssak M, Dufour S, Laurent D, Lebon V, Chandramouli V, Inzucchi SE, Schumann WC, Petersen KF, Landau BR, et al: Mechanism by which metformin reduces glucose production in type 2 diabetes. Diabetes 49: 2063-2069, 2000.

24. Reed MJ, Meszaros K, Entes LJ, Claypool MD, Pinkett JG, Gadbois TM and Reaven GM: A new rat model of type 2 diabetes: The fat-fed, streptozotocin-treated rat. Metabolism 49: 1390-1394, 2000.

25. Sharif S, van der Graaf Y, Nathoe HM, de Valk HW, Visseren FL and Westerink J; SMART Study Group: HDL cholesterol as a residual risk factor for vascular events and all-cause mortality in patients with type 2 diabetes. Diabetes Care 39: 1424-1430, 2016

26. Morton J, Zoungas S, Li Q, Patel AA, Chalmers J, Woodward M, Celermajer DS, Beulens JW, Stolk RP, Glasziou P, et al; ADVANCE Collaborative Group: Low HDL cholesterol and the risk of diabetic nephropathy and retinopathy: Results of the ADVANCE study. Diabetes Care 35: 2201-2206, 2012

27. American Diabetes Association: Diagnosis and classification of diabetes mellitus. Diabetes Care 36 (Suppl 1): S67-S74, 2013.

28. Nagashima S, Yagyu H, Takahashi N, Kurashina T, Takahashi M, Tsuchita T, Tazoe F, Wang XL, Bayasgalan T, Sato N, et al: Depot-specific expression of lipolytic genes in human adipose tissues - association among CES1 expression, triglyceride lipase activity and adiposity. J Atheroscler Thromb 18: 190-199, 2011.

29. Marrades MP, González-Muniesa P, Martínez JA and Moreno-Aliaga MJ: A dysregulation in CES1, APOE and other lipid metabolism-related genes is associated to cardiovascular risk factors linked to obesity. Obes Facts 3: 312-318, 2010.

30. Jernås M, Olsson B, Arner P, Jacobson P, Sjöström L, Walley A, Froguel P, McTernan PG, Hoffstedt J and Carlsson LM: Regulation of carboxylesterase 1 (CES1) in human adipose tissue. Biochem Biophys Res Commun 383: 63-67, 2009.

31. Shin DJ, Plateroti M, Samarut J and Osborne TF: Two uniquely arranged thyroid hormone response elements in the far upstream 5 ' flanking region confer direct thyroid hormone regulation to the murine cholesterol $7 \alpha$ hydroxylase gene. Nucleic Acids Res 34 3853-3861, 2006.

32. Noshiro M, Usui E, Kawamoto T, Kubo H, Fujimoto K, Furukawa M, Honma S, Makishima M, Honma K and Kato Y: Multiple mechanisms regulate circadian expression of the gene for cholesterol $7 \alpha$-hydroxylase (Cyp7a), a key enzyme in hepatic bile acid biosynthesis. J Biol Rhythms 22: 299-311, 2007.
33. Li T, Owsley E, Matozel M, Hsu P, Novak CM and Chiang JY: Transgenic expression of cholesterol $7 \alpha$-hydroxylase in the liver prevents high-fat diet-induced obesity and insulin resistance in mice. Hepatology 52: 678-690, 2010.

34. Fukami T, Nakajima M, Maruichi T, Takahashi S, Takamiya M, Aoki Y, McLeod HL and Yokoi T: Structure and characterization of human carboxylesterase $1 \mathrm{~A} 1,1 \mathrm{~A} 2$, and $1 \mathrm{~A} 3$ genes. Pharmacogenet Genomics 18: 911-920, 2008.

35. Yoshimura M, Kimura T, Ishii M, Ishii K, Matsuura T, Geshi E, Hosokawa $M$ and Muramatsu M: Functional polymorphisms in carboxylesterase1A2 (CES1A2) gene involves specific protein 1 (Sp1) binding sites. Biochem Biophys Res Commun 369: 939-942, 2008.

36. Gu S, Cao B, Sun R, Tang Y, Paletta JL, Wu X, Liu L, Zha W, Zhao C, Li Y, et al: A metabolomic and pharmacokinetic study on the mechanism underlying the lipid-lowering effect of orally administered berberine. Mol Biosyst 11: 463-474, 2015.

37. Murphy C, Parini P, Wang J, Björkhem I, Eggertsen G and Gåfvels M: Cholic acid as key regulator of cholesterol synthesis, intestinal absorption and hepatic storage in mice. Biochim Biophys Acta 1735: 167-175.

38. Li T and Chiang JY: Bile Acid signaling in liver metabolism and diseases. J Lipids 2011: 754067, 2012.

39. Denise R. Ferrier: Biochemistry. 6th edition. Peking University Medical Press, pp219-224, 2013

40. Memişoğullari R and Bakan E: Levels of ceruloplasmin, transferrin, and lipid peroxidation in the serum of patients with type 2 diabetes mellitus. J Diabetes Complications 18: 193-197, 2004

41. Logie L, Harthill J, Patel K, Bacon S, Hamilton DL, Macrae K, McDougall G, Wang HH, Xue L, Jiang H, et al: Cellular responses to the metal-binding properties of metformin. Diabetes 61: 1423-1433, 2012.

42. Schoonjans K, Watanabe M, Suzuki H, Mahfoudi A, Krey G, Wahli W, Grimaldi P, Staels B, Yamamoto T and Auwerx J: Induction of the acyl-coenzyme A synthetase gene by fibrates and fatty acids is mediated by a peroxisome proliferator response element in the C promoter. J Biol Chem 270: 19269-19276, 1995.

43. Suzuki H, Kawarabayasi Y, Kondo J, Abe T, Nishikawa K, Kimura S, Hashimoto T and Yamamoto T: Structure and regulation of rat long-chain acyl-CoA synthetase. J Biol Chem 265: 8681-8685, 1990

44. Saltiel AR and Kahn CR: Insulin signalling and the regulation of glucose and lipid metabolism. Nature 414: 799-806, 2001.

45. Tang Z, Zhang W, Wan C, Xu G, Nie X, Zhu X, Xia N, Zhao Y, Wang S, Cui S, et al: TRAM1 protect HepG2 cells from palmitate induced insulin resistance through ER stress-JNK pathway. Biochem Biophys Res Commun 457: 578-584, 2015.

This work is licensed under a Creative Commons Attribution-NonCommercial-NoDerivatives 4.0 International (CC BY-NC-ND 4.0) License. 